\title{
EVOLUTIONARY RESPONSES TO CHANGING CLIMATE
}

\author{
Margaret B. Davis, ${ }^{1,3}$ Ruth G. Shaw, ${ }^{1}$ and Julie R. Etterson ${ }^{2}$ \\ 'Department of Ecology, Evolution and Behavior, University of Minnesota, St. Paul, Minnesota 55108 USA \\ 2Department of Biology. University of Minnesota, Duluth, Minnesota 55812 USA
}

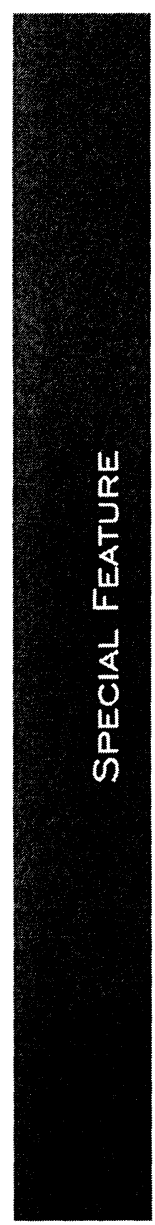

\begin{abstract}
Until now, Quaternary paleoecologists have regarded evolution as a slow process relative to climate change, predicting that the primary biotic response to changing climate is not adaptation, but instead (1) persistence in situ if changing climate remains within the species' tolerance limits, (2) range shifts (migration) to regions where climate is currently within the species' tolerance limits, or (3) extinction. We argue here that all three of these outcomes involve evolutionary processes. Genetic differentiation within species is ubiquitous, commonly via adaptation of populations to differing environmental conditions. Detectable adaptive divergence evolves on a time scale comparable to change in climate, within decades for herbaceous plant species, and within centuries or millennia for longer-lived trees, implying that biologically significant evolutionary response can accompany temporal change in climate. Models and empirical studies suggest that the speed with which a population adapts to a changing environment affects invasion rate of new habitat and thus migration rate, population growth rate and thus probability of extinction, and growth and mortality of individual plants and thus productivity of regional vegetation. Recent models and experiments investigate the stability of species tolerance limits, the influence of environmental gradients on marginal populations, and the interplay of demography, gene flow, mutation rate, and other genetic processes on the rate of adaptation to changed environments. New techniques enable ecologists to document adaptation to changing conditions directly by resurrecting ancient populations from propagules buried in decades-old sediment. Improved taxonomic resolution from morphological studies of macrofossils and DNA recovered from pollen grains and macroremains provides additional information on range shifts, changes in population sizes, and extinctions. Collaboration between paleoecologists and evolutionary biologists can refine interpretations of paleorecords, and improve predictions of biotic response to anticipated climate change.
\end{abstract}

Key words: adaptation; climate change; evolutionary constraints; Quaternary paleoecology: range shifts: tolerance limits.

\section{INTRODUCTION}

Adaptation to changes in the environment is an important and nearly universal aspect of biotic response to climate change. We argue here that adaptive responses affect species persistence, migration rate, and forest productivity. Thus more complete understanding of adaptive responses to climate must be incorporated into interpretations of Quaternary paleorecords. Furthermore, fossil records can provide tests of evolutionary hypotheses, enhancing understanding of the evolutionary consequences of climate change.

It is remarkable that paleoecologists reconstructing late-Quaternary environments so seldom discuss the possibility of adaptation to changing climate. They have tended to adopt the perspective of Darwin, who emphasized that vast periods of geologic time allow great opportunity for the accumulation of many slight differences among organisms that, collectively, can re-

Manuscript received 24 November 2003; accepted 16 June 2004; final version received 4 October 2004. Corresponding Editor (ad hoc): L. J. Graumlich. For reprints of this Special Feature, see footnote 1, p. 1667.

3.E-mail: mbdavis@ecology.umn.edu sult in major differences in biological form. Accordingly, a fundamental assumption of paleoecology has been that the rate of evolution is far slower than the rate of climate change (Bennett 1997, Webb 1997, Jackson 2000), with meaningful evolutionary adaptations, such as the origination of taxa, occurring on the timescale of millions of years. Climate changes much more rapidly, because superimposed on glacial cycles 100000 years in length are variations on millennial, centennial, and even decadal time scales. For example, during the most recent glacial-interglacial transition, a time of rapid warming, there was a brief reversal lasting several centuries. At this time paleorecords from the north Atlantic region record a temperature drop of several degrees C within decades (Huntley et al. 1997). Paleoecologists have argued that such rapid environmental changes overwhelm evolutionary processes, causing extinction except where climate remains within preexisting tolerance limits for a species (Bennett 1997). Contributing to this view has been the sparseness of the record of new plant species during the Quaternary and the apparent limitations of fossils, especially pollen, to record traits involved in adaptation to climate, such as phenology and physiology. Further- 
more, latitudinal range shifts of tree taxa, well documented in Quaternary sediments, are compatible with the view that species persist only within the environments to which they are already adapted, even as those environments shift in space (Prentice et al. 1991, Jackson 2000).

Moreover, paleoclimate reconstructions rely on the premise that each species has a unique set of limits in its tolerance to various aspects of the environment, defining a multidimensional ecological niche (Jackson 2000). Paleoecologists have focused on physical niche dimensions, determining for particular species the realized limits of physiological tolerances to factors such as minimum temperature or growing degree days. When species-specific tolerances are plotted on a map of modern climate, they quite accurately delimit the present geographical distribution of the species in question (Peterson et al. 1999). Paleoclimate reconstruction employs these environmental attributes of species to infer the distribution of climate at an ancient time from the distribution and abundance of fossils. Thus, paleoclimate reconstruction depends on the assumption that species tolerance limits remain stable in time, that is, evolutionarily inert. In practice, a certain amount of change might not be noticed because reconstructions are often at a coarse geographical scale (Prentice et al. 1991), with broad confidence intervals surrounding temperature and precipitation estimates. Fossil records used for validation are often sparse, especially for older time horizons. Nevertheless, recent reviews regard rapid evolution as the exception, affecting only "some local populations of a species ... while others undergo extinction or disperse to newly suitable sites" (Jackson 2000:294). Given this context, discussions of biotic response to future climate emphasize predicted range shifts, focusing on seed dispersal and establishment as potentially limiting processes (e.g., Clark et al. 1998).

Here we consider evolution in relation to climate and discuss its relevance to processes paleoecologists consider important, including population persistence in situ, range shifts, and extinction. We review the evidence for adaptation of plant populations to spatial variation in environment and discuss the potential for evolutionary response to temporal variation. We emphasize that climate change on various time scales imposes selection regimes that may lead to adaptive changes in plants and animals, whether or not their ranges shift (Davis and Shaw 2001). The degree of adaptation depends on the interplay of natural selection with other evolutionary processes, such as gene flow, genetic drift, and mutation, and also with demography. A lag in adaptation implies reduction in growth and survival of individual plants as well as in the overall productivity of regional vegetation (Rehfeldt et al. 1999, 2002). The rate of adaptation influences the rate at which populations invade newly available habitat (García-Ramos and Rodriguez 2002), and also the probability that populations will die out within their present ranges (Pease et al. 1989, Burger and Lynch 1995). Thus, adaptive evolution affects all of the primary responses to changing climate predicted by paleoecologists-"tolerance, migration, or extinction" (Jackson 2000:294). We reinterpret examples from the Quaternary record that demonstrate how evolutionary models can expand understanding. Last, we review recent contributions by Quaternary paleoecologists that utilize paleorecords to demonstrate adaptations to environmental change.

\section{Genetic Change in Plants DURING THE QUATERNARY}

For animal phyla, particularly mammals, both speciation events and extinctions are well documented during the past two million years. In contrast, the Quaternary fossil record documents few examples of new species of vascular plants (Comes and Kadereit 1998), reinforcing the impression that, particularly in these organisms, evolution is a slow process. Speciation is, however, only one aspect of evolutionary change. Within species, genetic differentiation among populations attests to the ubiquity and rapidity of evolutionary change.

Spatial substructuring of populations is evidenced by variation at putatively neutral genetic marker loci, reflecting current mating patterns and/or previous isolation of populations. Phylogeographers use such markers as a basis for inferring locations of refuges during the last glaciation, and pathways of migration since then (e.g., Cruzan and Templeton 2000, Hewitt 2000). Fossil evidence has valuably informed such studies. For example, allozyme and mitochondrial DNA (mtDNA) divergence has been calibrated against the actual time since isolation of tree populations in the American Southwest. Time of isolation was determined from migration histories documented by macroremains preserved in packrat middens (Hamrick et al. 1994). Allozymes in a series of populations of lodgepole pine (Pinus contorta), the ages of which were determined from radiocarbon-dated fossil-pollen records, suggest a progressive loss of alleles in the course of northward migration in western Canada during the Holocene (Cwynar and MacDonald 1987). Reduced allelic diversity away from putative glacial refugia has been documented for several plant species, while Pinus pumila shows reductions in diversity at some loci and increased diversity at others (Tani et al. 1996).

Adaptative differentiation among populations within a species is documented by clinal variation in physiological, phenological, and fitness traits in relation to latitudinal or elevational gradients in climate. Such variation has been shown for many species, beginning with the classic studies of Turesson (1922) and Clausen et al. (1940) and continuing with recent papers too numerous to list here. The distribution of climate-sensitive traits within species is studied in common-garden (provenance) experiments, in which plants from different geographical locations are grown together at a 

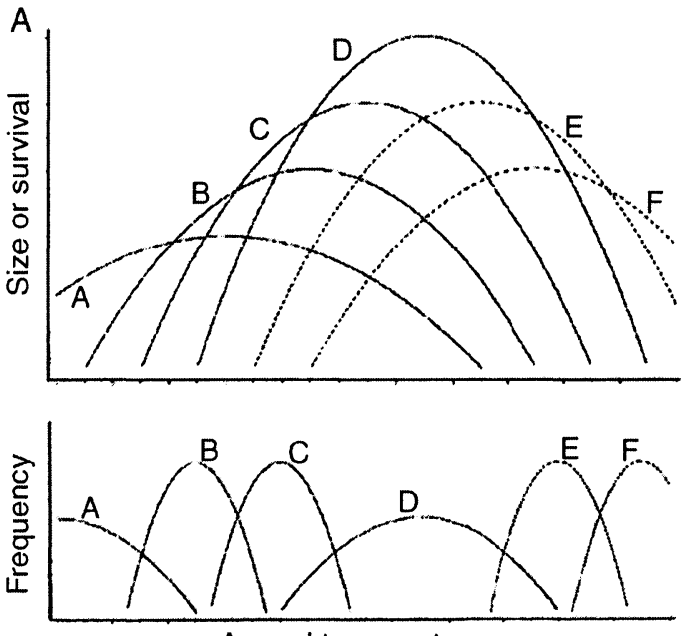

Annual temperature
B

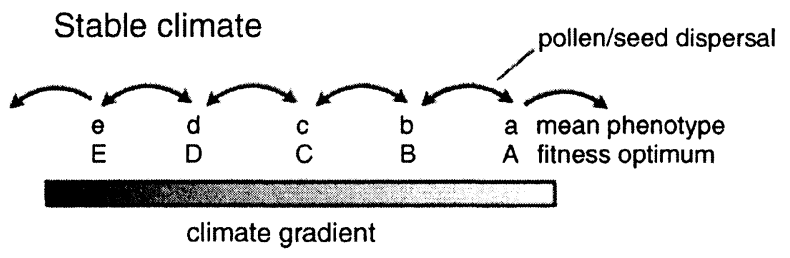

Changing climate

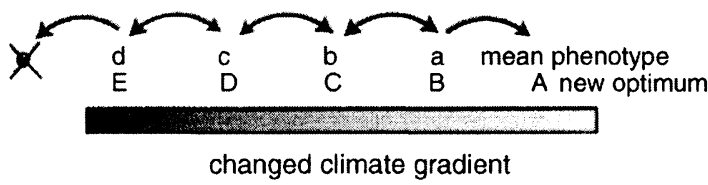

FIG. 1. (A) Diagrammatical representation of the growth and mortality response of trees to gradients in the mean annual temperature (fundamental niche) (top), and the frequency of occurrence of the same populations (realized niche) across the same temperature gradient (bottom). Diagrams are generalized from common-garden studies of Pinus contorta in western Canada. (Panel A is reproduced from Rehfeldt et al. [1999].) (B) Diagram depicting hypothetical phenotypic means and optimal fitness means of populations of a plant species along a climate gradient under a stable climate (top), and under a changing climate (bottom). In time, the changed selection regime will bring the phenotypic means of local populations closer to the changed fitness optima. Meanwhile, the range is shifting in space as populations spread into newly suitable habitat at one end of the gradient and retreat from unsuitable habitat at the other end of the gradient. (Panel B is modified from Davis and Shaw [2001].)

series of locations with differing climate, or as a special case of this approach, are transplanted reciprocally into the different sites from which populations are sampled. These studies show that most tree and herbaceous plant species comprise a series of populations, each of which is relatively well adapted to its local environment (Fig. 1; see e.g., Reinartz 1984, Lacey 1988, Rehfeldt et al. 1999, 2002, Etterson 2004a; also see Plate 1). For many tree populations, growth rates are highest at test sites with temperatures similar to the source location; growth tends to be less and mortality greater at both warmer and colder locations (Carter 1996) (Fig. 2). Thus, a novel climate reduces individuals' growth, as well as survival and fecundity, i.e., fitness. The reduction can be large: for example climate differences predicted for doubled concentrations of greenhouse gases could reduce biomass production by $20 \%$ in Canadian populations of lodgepole pine (Rehfeldt et al. 1999) and reduce seed production by $30 \%$ in some herbaceous species (Etterson 2004a).

Numerous examples document the speed of adaptive differentiation. For example, adaptation of Scots pine (Pinus sylvestris) to the diverse elevations and latitudes it currently occupies in Finland (Muona 1989, Hurme et al. 1997) must have happened within the past several thousand years at most, because the region was covered by continental ice until the mid-Holocene. Similarly, studies of introduced herbaceous species in North America and Europe show that genetic differentiation and clinal variation in response to climate has accrued since the time of establishment on the continent, i.e., within decades or a century (Verbascum thapsus, Reinartz 1984; Daucus carota, Lacey 1988; Solidago sp., Weber and Schmid 1998).

To the extent that spatial differences in climate elicit the expression of genetic variation in fitness, a temporal change in climate will also impose a new selection regime, under which traits may evolve adaptively. When climate changes, fitness may be reduced initially, but after a number of generations populations throughout a species range could, via selection response, recover the fitness and biomass they exhibited before the onset of climate change. Is adaptation of all populations to a new climate gradient equally likely? And how many generations would it require for fitness and productivity to match those prior to climate change? Of course the magnitude and rate of climate change and its duration are critical. But answers will also depend upon the ecological breadth of individual genotypes, the distribution and nature of genetic variation for relevant traits, the extent of gene flow among populations through dispersal of both pollen and seeds, and the demographic flux of populations. The potential for adaptive evolution may also be influenced by changing competition among species that differ in their response to climate change. To date, stand-simulators examining forest response to changing climate have not considered these issues because they treat species as collections of identical individuals rather than taking genetic variation into account. 


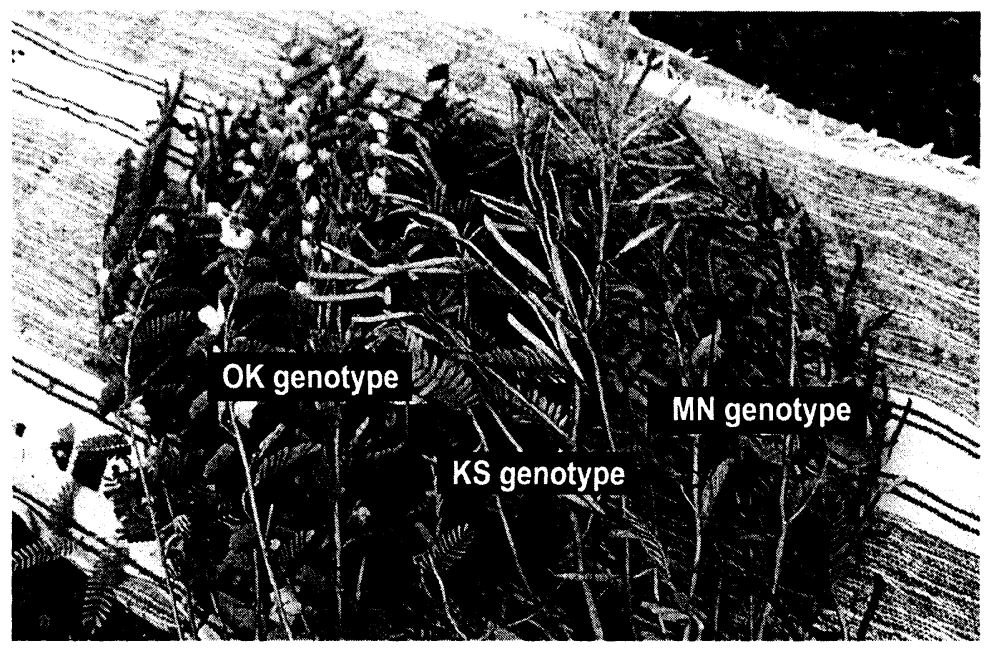

PLATE 1. Illustration of genetic differentiation in the rate of phenological development of populations of Chamaecrista faciculata sampled from an environmental gradient across the Great Plains. These plants were grown in a common garden in Minnesota and sampled in early October just prior to the first hard frost. (Right) Minnesota genotype with fully ripening pods. (Middle) Kansas genotype in the process of pod maturation. (Left) Oklahoma genotype at the peak of flowering. Photo credit: J. R. Etterson.

Genetic variation means that climate changes will affect populations differently throughout a species range, and populations will vary in the rate of adaptation. This point is illustrated by lodgepole pine, jack pine, Scots pine, and Siberian larch, which have been extensively studied in provenance trials. Although

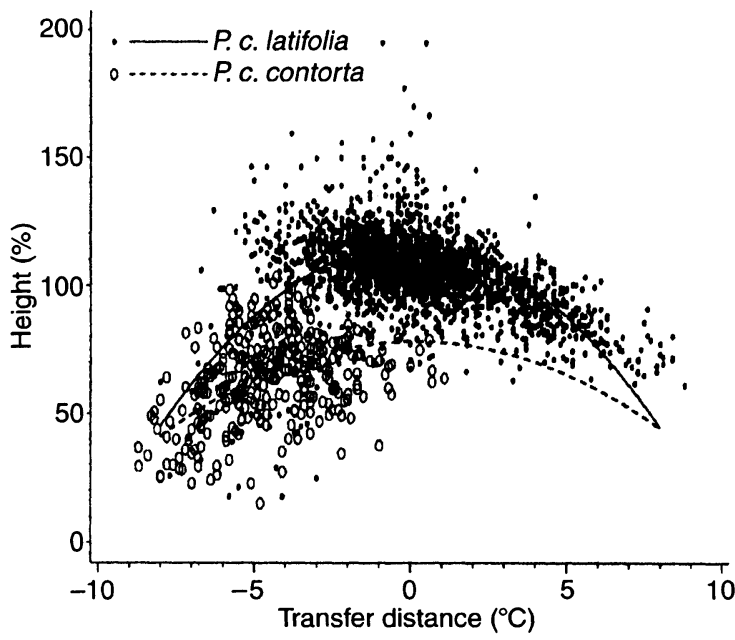

FIG. 2. The 20-yr height (percentage of plantation mean) of 118 populations of Pinus contorta ssp. latifolia (black dots) and ssp. contorta (open circles) grown at 60 test sites in western Canada. Growth is plotted against the difference of mean annual temperature between the planting site and the site of origin. Positive values denote transfers into a warmer climate; negative values denote transfers into a colder climate For these populations, growth is maximal at test sites with climate closely similar to the climate at the site of origin. (The figure is reproduced from Rehfeldt et al. [1999].) many populations grow best in climates similar to their place of origin, northern populations of each of these conifers grow more rapidly in warmer climates than in the climates they actually occupy (e.g., population A in Fig. 1) (Rehfeldt et al. 1999, 2002, 2004). Rehfeldt et al. (2004) attribute the phenomenon to a negative genetic relationship between tree growth rate and cold hardiness, speculating that cold-tolerant genotypes are outcompeted during stand thinning by faster-growing cold-intolerant genotypes. The discrepancy between optimal and realized growth environments means that climate warming could represent a change to which the northern populations readily adapt. Even for these newly established populations, however, differences in photoperiod or other aspects of the environment can impose selection. At the southern edge of a species' range, in contrast, populations may grow poorly in warmer conditions. Here, populations could be extirpated rapidly as climate warms to levels outside the tolerance limits of individual trees. In the center of the range, novel climate will reduce individual growth rates and increase mortality of existing genotypes; thus productivity of forests dominated by any of these conifers will be reduced, at least in the short term, even in the center of the range (Rehfeldt et al. 1999, 2002, 2004).

\section{Genetic Constraints on Future Adaptation}

The rate at which adaptation can proceed is critical for predicting plant response to climate change. Trees produce seeds copiously, and, despite the failure of many seeds to germinate, thousands of seedlings es- 
TABLE 1. Demography of sugar maple (Acer saccharum), 1991-1998, in plot A, Sylvania Wilderness Area, Gogebic County, Michigan, USA.

\begin{tabular}{ll}
\hline \hline \multicolumn{1}{c}{ Parameter } & \multicolumn{1}{c}{ Value } \\
\hline Seeds (range of annual values) & $3000-10000000 \mathrm{seeds} \cdot \mathrm{ha}^{-1} \cdot \mathrm{yr}^{-1}$ \\
Seedlings & 725000 seedlings $/ \mathrm{ha}$ \\
Saplings and understory trees & $500 \mathrm{individuals} / \mathrm{ha}$ \\
Canopy trees & $145 \mathrm{trees} / \mathrm{ha}^{-1}$ \\
Trees reaching canopy (average, 1991-1995) & 1 tree $\cdot \mathrm{ha}^{-1} \cdot \mathrm{yr}^{-1}$ \\
\hline
\end{tabular}

tablish each year (Table 1). This prolificacy from sexual reproduction facilitates exposure of the available genetic variation to selection. A miniscule fraction of each cohort of seeds and seedlings survives to reach the forest canopy and reproduce (Table 1). Over the several decades that juveniles are thinned from a forest stand, selection could increase the frequency of genotypes that tolerate novel climate conditions. Rehfeldt et al. $(1999,2002)$ use data from generational changes in growth rate in selection experiments to estimate that recovery of adaptation following anticipated warming in coming decades would require one to 13 generations for particular populations of lodgepole pine and Scots pine. Thus, adaptation of these long-lived trees could require as little as a century for the northern populations that grow well under warmer conditions, but well over a millennium for central and southern populations that grow poorly under warmer conditions. These estimates assume sufficient genetic variation, but 10 or more generations of strong directional selection could severely reduce genetic variability available to support selection response.

Depletion of variability is only one of the genetic constraints that could impede adaptation to changing climate. A recent study of the prairie annual, Chamaecrista fasciculata, demonstrates that genetic correlations among traits important for fitness may impede adaptive evolution under a warmer and drier climate (Etterson and Shaw 2001). Pedigreed seedlings were reciprocally planted in common gardens along an aridity gradient in the Great Plains. Traits that influence fitness were measured, including the rate of phenological development, leaf number, and leaf thickness. Clines in selection corresponding to latitude were observed and are predicted to move northward in the future (Etterson 2004a). Populations harbored genetic variation for most traits under selection, although the amount was lower at the periphery of the species range (Etterson 2004b). Despite significant selection and genetic variance, the rate of adaptive evolution in these populations is predicted to be slower than the anticipated rate of climate change. Adaptive evolution may be substantially slowed because of genetic correlations among traits that are antagonistic to the direction of selection under a changed climate (Fig. 3, Etterson and Shaw 2001). The genetic correlations are due either to pleiotropy, in which the effect of an allele on one trait, e.g., leaf thickness, enhances fitness, whereas its effect on another trait, e.g., rate of phenological development, reduces fitness, or to linkage disequilibrium, the association of alleles at different loci. Adverse genetic correlations may reduce the likelihood that combinations of traits that result in highest fitness in hotter, drier climates will evolve. The lability of genetic correlations among traits and thus the extent of genetic constraint, depends on the genetic nature of the correlation (pleiotropy, linkage disequilibrium), which is not readily determined. The extent of genetic impediments to adaptation to climate change is generally poorly known, but impediments to adaptation are particularly important today, as the future rate of change in climate is predicted to exceed past changes by at least one order of magnitude.

Despite these potential impediments, evolutionary response to change in physical conditions has been shown in a number of different species. Experiments in bacteria demonstrate both adaptation to changed temperature regime and lability of species tolerance limits. Replicate lines of the bacterium E. coli, all derived from a single cell, were subjected to directional selection under distinct temperatures throughout the range typically tolerated, and one set of lines was subjected to variable temperatures $\left(10^{\circ} \mathrm{C}\right.$ diurnal range; Lenski 2001). Over 2000 generations, each population adapted to the temperature it experienced, with the rate of increase in fitness, relative to the ancestor, greatest at the highest temperature used, $42^{\circ} \mathrm{C}$, within a degree of the lethal limit (Bennett et al. 1992). Lines subjected to variable temperature evolved increased fitness throughout a $20^{\circ} \mathrm{C}$ range of temperatures, broader than the range over which fitness increased for any of the lines held at constant temperatures (Bennett et al. 1992, Lenski 2001). This argues against the view that variable climate, as experienced during the Quaternary Period, generally impedes adaptation. Further investigation of the evolutionary potential to extend the range above $42^{\circ} \mathrm{C}$ revealed that mutations conferring tolerance to higher temperatures consistently reduce competitive performance (Mongold et al. 1999). Consequently, in these $E$. coli cultures, adaptation to temperature more extreme than that tolerated by the ancestral population evolves only in declining populations. However, once populations reached a critical low density, new mutations conferring tolerance of higher temperatures did increase in frequency. These studies demonstrate the role of genetic constraints in evolution under changing 


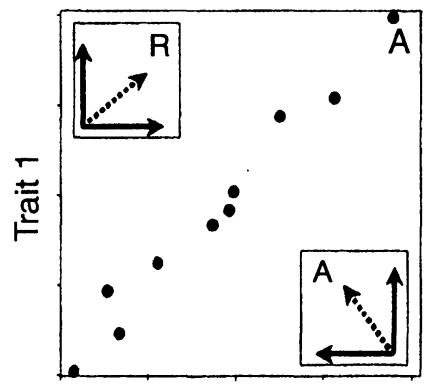

Trait 2
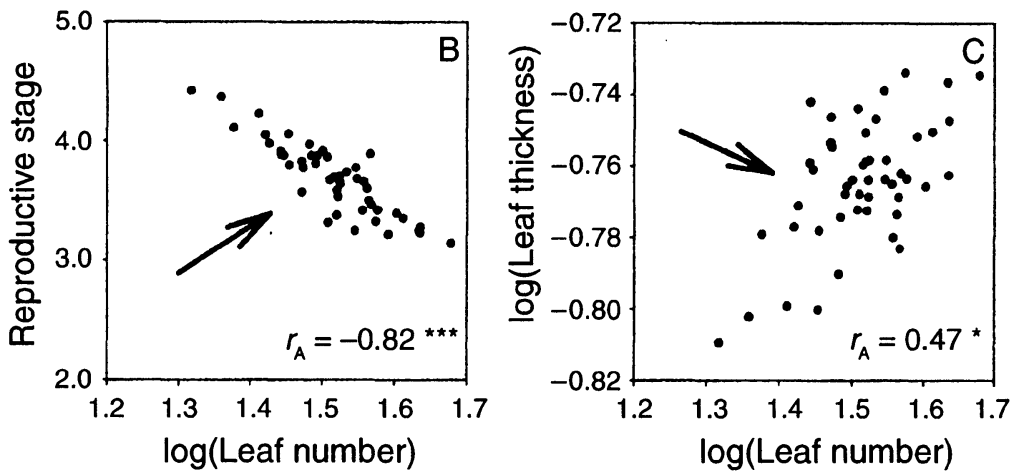

FIG. 3. Illustration of the influence of genetic correlations among traits on selection response, reproduced from Etterson and Shaw (2001). (A) Hypothetical positive genetic correlation between two traits (each point represents the breeding value, similar to a family mean, for each of two traits). There are two selection scenarios: for R (reinforcing selection), the depicted $r_{\mathrm{A}}$ (correlation between traits) is in accord with the direction of selection, enhancing evolutionary response; for A (antagonistic selection), the depicted $r$ (correlation between traits) is in the opposite direction from selection, inhibiting evolutionary response. (B) Scatter plot of reproductive stage and leaf number breeding values for a Minnesota population of Chamaecrista fasciculata when grown in the hotter, drier climate of Oklahoma, showing significant negative genetic correlation that is antagonistic to the positive vector of joint selection on these traits. (C) Scatter plot of the Minnesota population leaf thickness and leaf number breeding values, showing a significant positive genetic correlation that is also antagonistic to the negative vector of joint selection. Both (B) and (C) are examples of adverse correlations between traits that are predicted to limit adaptive evolutionary response of Minnesota populations of this species under conditions of higher temperature and soil moisture stress.

climate. Most importantly, they demonstrate the evolutionary lability of limits of environmental tolerance, even when genetic variation is restricted to variation generated by spontaneous mutation. Clearly, when influx of variation due to mutation is added to the standing genetic variation already present in populations of diploid organisms, tolerance limits for a species or population should not be regarded as fixed.

\section{EVOLUTIONARY MODELS INFORM INTERPRETATION OF THE PALEORECORD}

Interpretations of fossils often assume stability of species tolerance limits. This issue is examined in recently developed evolutionary theory, which considers the interplay of evolutionary and demographic processes in the evolution of tolerance limits. The differential population growth rates of central and peripheral populations appear to produce a bias toward stability of tolerance limits. Gene flow from more central populations through pollen or seed dispersal overwhelms genetic adaptation in the much smaller peripheral populations, reducing fitness (Antonovics 1976, GarcíaRamos and Kirkpatrick 1997).

Although paleoecologists generally assume constancy of environmental tolerance limits, paleoecological data can sometimes be used to test the hypothesis that limits have changed over time. An example is a study that predicts fossil pollen distributions at various time horizons from global climate model output, using transfer functions derived from patterns of modern pollen and modern climate (Prentice et al. 1991). Predictions of oak pollen distributions in North America during the last glacial maximum and at various time horizons within the Holocene appear to correspond well with the distributions of fossils (Fig. 4a), suggesting that the relationship between climate and pollen abundance has remained stable over the past 24000 years for the more than two dozen eastern North American oak species considered collectively. However, spruce pollen distribution is underpredicted by the model 24000,21000 , and 16000 calendar years ago (Fig. 4b). In this case a probable explanation is greater breadth of tolerance limits in the past for the genus Picea because the extinct spruce species, Picea Critchfieldii, was distributed widely in southeastern United States. This species, known only from fossil remains, was apparently adapted to warmer climate than other eastern American spruce species, given its co-occurrence with temperate deciduous trees in the southern Mississippi valley. It died out around 15000 years ago (Jackson and Weng 1999). Ackerly (2003) suggests that diminished competition from congeners might promote adaptation of trailing-edge species to changing climate, but in this case extinction occurred instead, even as other spruce species migrated northward. Climate changes were exceptionally rapid at the time Picea Critchfieldii became extinct, in some regions rivaling in speed future changes predicted to result from greenhouse warming (Huntley et al. 1997).

A third illustration is provided by eastern hemlock (Tsuga canadensis). The distribution of pollen from this tree species in the three oldest time horizons is overpredicted by the climate model (Fig. 4c). Overprediction using parameters derived from modern populations suggests that tolerance limits for this species might have been narrower in the past than they are at 
A) Oak, observed
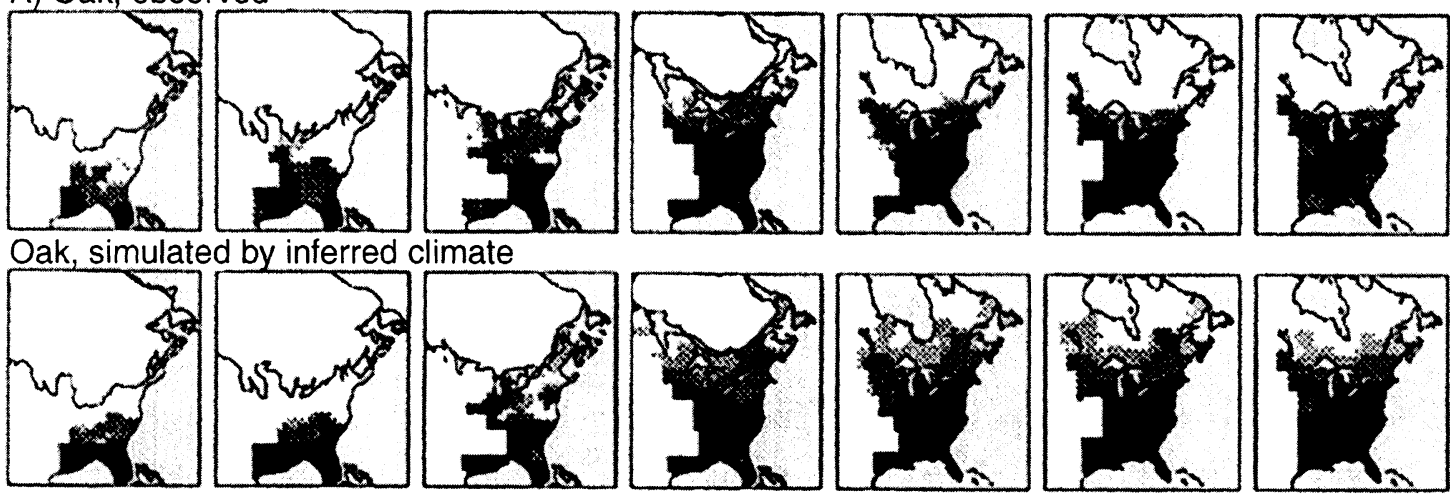

B) Spruce, observed
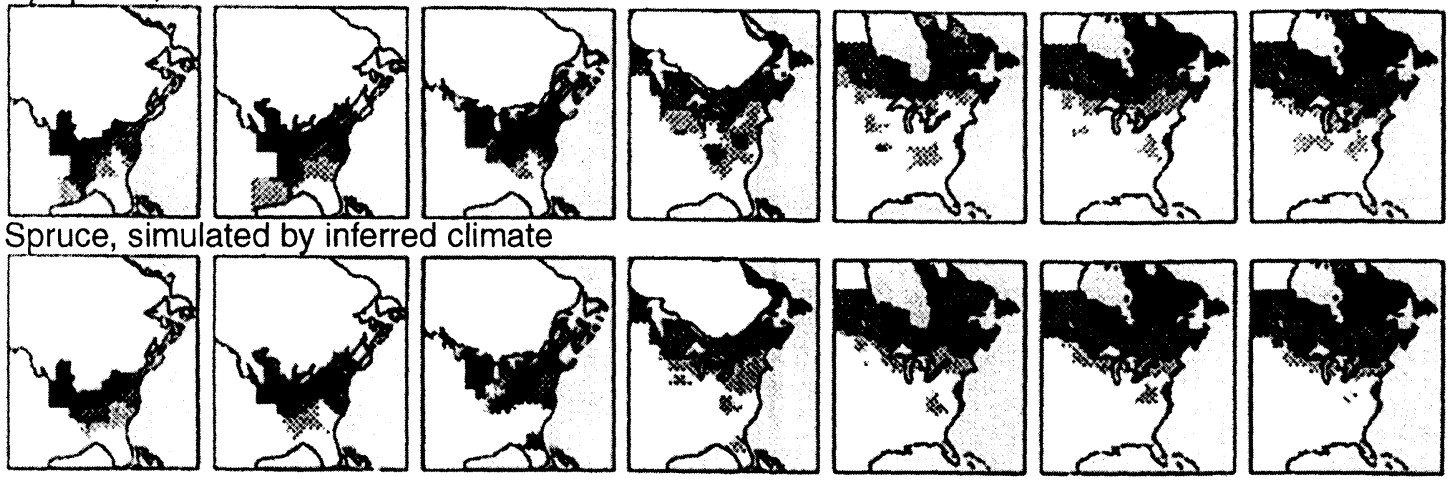

C) Hemlock, observed
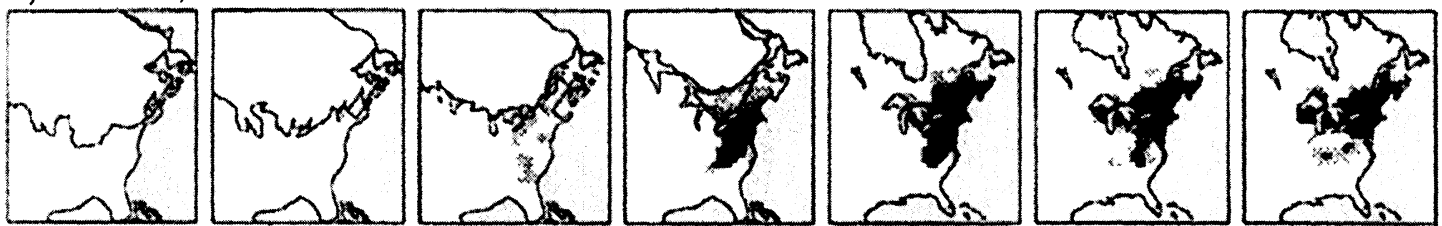

Hemlock, simulated by inferred climate

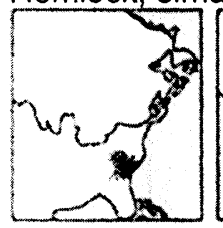

24000

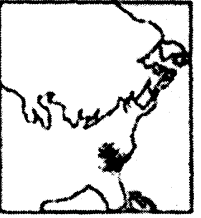

21000

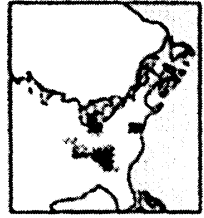

16000

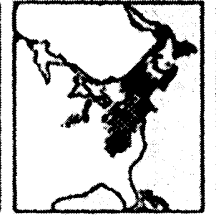

11000

cal yr BP

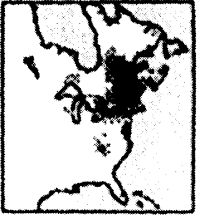

6000

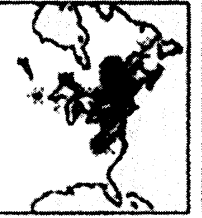

3000

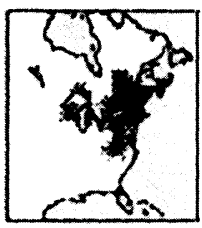

0

Fig. 4. (A) Fossil oak (Quercus spp.) pollen abundance in eastern North America during the full-glacial (24000 years ago) and six younger time intervals, compared to pollen abundance predicted from climate model output, using transfer functions derived from modern pollen and climate. Time is expressed in calibrated years before 1950 . Observed and predicted abundance correspond well. (B) Similar comparisons for spruce (Picea spp.). In this case, pollen abundance is underpredicted for the three oldest time horizons, suggesting broader environmental tolerances at that time than at present, perhaps because the extinct species Picea Critchfieldii was still present. (C) Similar comparisons for eastern hemlock (Tsuga canadensis). The location of the hemlock refuge (judged from locations where hemlock pollen first appears) is correctly predicted, but population density is overpredicted at the earlier time horizons, when latitudinal temperature gradients were steeper than today. One explanation is a narrowing of the tolerance limits of the species at that time. Predictions correspond better to fossil records deposited during the last $6000 \mathrm{yr}$. (The figure is modified from Prentice et al. [1991].) 


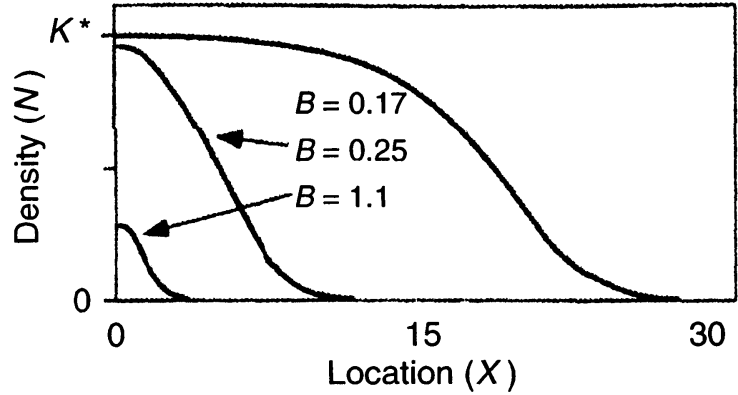

FIG. 5. Theoretical depiction of population density along an environmental gradient. $X$ indicates location along the gradient, only half of which is shown in the figure. $X=0$ where the environment is optimal for the species. $B$ is an index of the steepness of the gradient. When $B$ is small, population density is at carrying capacity $K^{*}$ wherever environmental conditions are close to optimal, and the environmental amplitude for the species is large. When $B$ is large, indicating a steep gradient, population density falls to low levels, gene migration overwhelms marginal populations, and range limits contract. (The figure is reproduced from Kirkpatrick and Barton [1997].)

present. Of course, errors may explain the overprediction, for example, problems in the climate predictions or errors in evaluating the climate-pollen transfer function. Background vegetation with higher pollen productivity suppressing hemlock pollen percentages is a third possibility.

Kirkpatrick and Barton (1997) develop a model that offers a possible evolutionary explanation for this discrepancy, considering that latitudinal temperature gradients were steeper than today during the last glacial maximum. Their model investigates adaptation in a series of populations along an environmental gradient (Fig. 5). Parameters describe gene flow and steepness of the environmental gradient ( $B$ in Fig. 5). When the gradient is gradual, pollen and seed dispersal bring to each adjacent population genes selected in similar environments. Under this circumstance, marginal populations in the model may adapt to extreme conditions, and the species tolerance limits and geographic range expand. When the environmental gradient is steep, however, populations subject to drastically different environmental conditions are growing in close juxtaposition, and gene flow from more central populations may overwhelm adaptation in marginal populations, such that they become demographic sinks or go extinct. In this way, both the species boundary and physiological tolerance range can shrink. We note, however, that more recent work of Barton (2001) demonstrates that the outcome, in which limits to a species range evolve, is highly sensitive to Kirkpatrick and Barton's (1997) assumption of constant genetic variance. The plausible alternative, in which genetic variance evolves along with trait means, can lead to indefinite range expansion. Because genetic details that would influence the evolution of variance of quantitative traits are elusive, it is not possible at present to assess how applicable these different cases are to particular species.

Latitudinal temperature gradients are anticipated to become less steep in future as high latitudes warm more rapidly than low latitudes under the influence of greenhouse gases. This scenario was examined by GarcíaRamos and Kirkpatrick (1997). They modified the Kirkpatrick-Barton model to examine population dynamics and genetic changes within a population along a climate gradient that varied in steepness. Lessening of the gradient in the model increased the speed of adaptation and thus the expansion rate for marginal populations invading new habitat.

Case and Taper (2000) extended the Kirkpatrick-Barton model to explore the interaction between environmental gradients and interspecific competition. Along environmental gradients, competition from neighboring species plays a critical role by reducing densities of marginal populations, augmenting the effect of gene flow from populations nearer the center in swamping out adaptations to local environments. Case and Taper examined different scenarios in which interspecific competition interacts with environmental gradients of varying steepness to limit the sizes of species ranges. Gomulkiewicz and Holt (1995) have modeled the problem of adaptation in populations that are sufficiently maladapted that they persist only as a result of immigration, "black-hole sinks." They investigated conditions under which the population evolves such that its growth becomes positive before its numbers decline to zero. Their model shows that, the smaller the sink population and the more maladapted it is, the more likely it is that it will become extinct before it achieves a positive growth rate. The consequence, in this instance, is that the range contracts.

The effect on evolutionary response of temporal continuity in the trajectory of environmental change is addressed by Pease et al. (1989). These authors used a model to examine the relative importance of evolution, migration and habitat selection to population fitness in the course of a range shift induced by continuously changing climate. They modeled a population with maximum fitness at a point along a climate gradient. Environmental parameters affecting fitness changed steadily through time at all points along the gradient. If climate changed sufficiently slowly, the species persisted, shifting its range along the climate gradient. Persistence of the species also depended on genetic variability and the pace of evolutionary adaptation to the changing climate.

Evolution in an environment undergoing constant temporal change has also been modeled by Bürger and Lynch (1995). With effects of mutations on phenotypes symmetrically distributed around zero, they found that the mean phenotype evolves in a lag behind the phenotypic optimum as the optimum changes with changing environment. The chance of extinction depends on the magnitude of this lag, which, in turn, depends both 
on the rate of environmental change and on the influx of variation due to mutation. It will complicate this scenario to consider climate variability on the many different time scales that paleoecologists find superimposed on long-term climate trajectories.

Depictions of climate in genetic models are increasingly sophisticated. Older models imposed a stepchange in climate, preceded and followed by climate stasis, whereas these more recent papers incorporate paleoclimate reconstructions and the predictions of global climate models.

\section{USING THE Fossil RECORd to TEST EVOLUTIONARY HYPOTHESES}

Paleorecords reveal changes in past distribution and abundance of plant and animal species. This information provides a historical context that can be used in conjunction with studies of contemporary genetic patterns to test evolutionary hypotheses (e.g., Hamrick et al. 1994). Well-preserved fossils are now providing direct evidence of evolutionary changes coincident with environmental change, supplementing the information derived from neutral markers in contemporary populations. Recently, DNA recovered from Daphnia eggs in lake sediments several decades in age, and from fossil pollen grains 150000 years old has provided identifications at the species level, refining our understanding of the historical distributions of species (Suyama et al. 1996, Hairston et al. 2005). Like the discovery of Picea Critchfieldii, such identifications illuminate the role of individual species in ecosystem processes, and bear on the lability of species' tolerance limits under changed climates of the past.

The new field of "Resurrection Ecology" goes a step further, reviving propagules of plants and animals preserved in sediment deposited at different time horizons, and directly comparing the environmental responses of the resulting "resurrected" populations. Seeds of two graminoid species, buried in arctic soils by solifluction lobes over a century earlier, were germinated and grown in common conditions with seeds from much younger soil horizons. Significant differences in physiological response to temperature were found for these perennial plants (Fig. 6A) (McGraw and Fetcher 1992).

Similarly, evolutionary changes in zooplankton have been observed in populations hatched from resting eggs buried in lake sediments (see references cited in Hairston et al. 2005). For example, comparison of Daphnia subpopulations dating from successive time horizons ranging from 0 to 35 years in age permitted direct observation of a time series of traits associated with fitness. In this study, the physiological responses of Daphnia demonstrated evolutionary adaptation on the decadal time scale: clones of Daphnia from modern, eutrophic Lake Constance are significantly more resistant to toxin-containing cyanobacteria than clones originating from 35-year-old resting eggs deposited before cyanobacteria became abundant (Hairston et al. 1999)
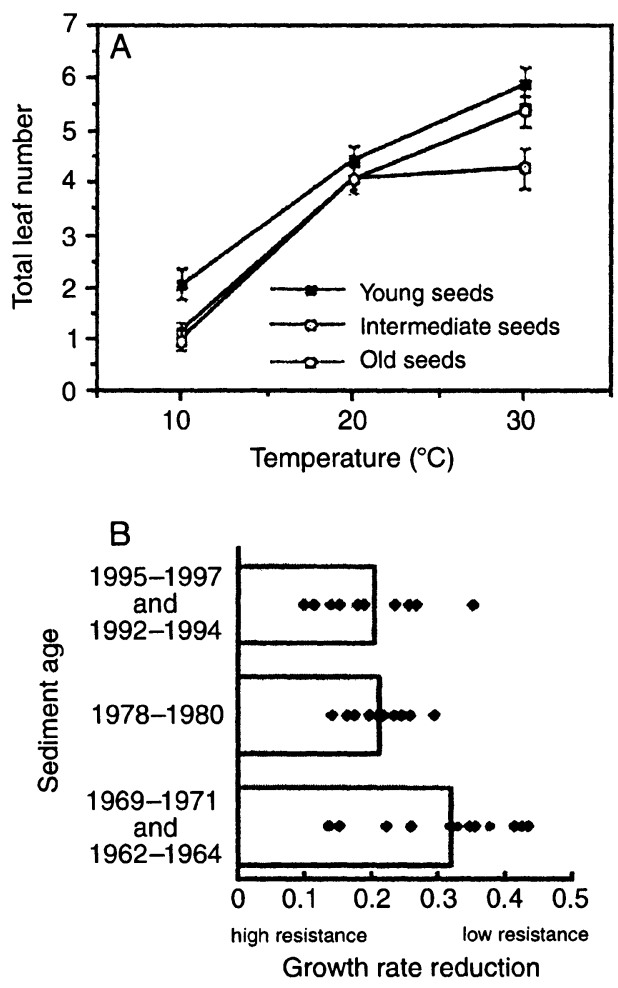

FIG. 6. (A) Differential response to temperature under growth-chamber conditions of Carex bigelowii subpopulations resurrected from seeds of different ages buried under solifluction lobes. The oldest seeds are $\sim 175$ yr old; the youngest seeds are $0-20 \mathrm{yr}$ old. (Panel A is reproduced from McGraw and Fetcher [1992], with permission from Elsevier.) (B) Differential sensitivity to cyanobacteria toxin of subpopulations of Daphnia hatched from resting eggs recovered from Lake Constance sediment. The oldest populations date from 1962-1971, and the youngest from 1992-1997. Cyanobacteria began to increase during the late 1960 s, reached high levels by 1970, and have remained abundant subsequently. At the same time, Daphnia populations developed increased resistance to cyanobacteria toxins. (Panel B is reproduced from Hairston et al. [1999], with permission from Nature.) Both examples (A) and (B) demonstrate changes in adaptive traits on the decadal time scale.

(Fig. 6B). In Lake Superior, Daphnia resurrected from sediments dating from early in the 20th century up to the present document rapid morphological change and species replacement, as dredging and enrichment changed the near-shore environment (Kerfoot et al. 1999). Using similar methods, Hairston et al. (2005) document the effects on a lake ecosystem of species replacements induced by industrial contamination during the past half-century.

Resurrected populations include only the last 150 years (so far). Nevertheless, they demonstrate evolutionary change in adaptive traits, even in organisms with relatively long generation times. They provide strong evidence against the idea that rapid environmental change overwhelms evolutionary processes, 
preventing adaptation to local environments as they vary in time and space (Webb 1997, Jackson 2000).

\section{CONCLUSIONS}

Adaptive responses to climate, while clearly important, are not yet well understood. Future research should have the goal of determining the pace of adaptive changes in different species and groups of organisms. How closely can adaptation be expected to track climate change, particularly changes as rapid as envisioned for the future? How will adaptation be affected by changed environmental gradients? We have reviewed several processes that might limit rates of adaptation to changing climate. But how prevalent and how strong are evolutionary constraints due to adverse genetic correlations among traits, as encountered in Chamaecrista fasciculata (Etterson and Shaw 2001) and $E$. coli (Mongold et al. 1999), and how persistent will they be? Do differences in rates of adaptation among organisms differing in breeding systems, spatial genetic structure, or demographic properties account for phenomena observed in the fossil record, such as different migration rates? Does adaptation explain why some species survived as tiny populations in multiple refuges, while others maintained continuous populations, shifting to different latitudes? Can differences among taxa in rates or degrees of adaptation explain why some ancient forest communities have no analogue at present? Do differences in rates of adaptation to changing environments determine which taxa persist and which become extinct?

Answers to these questions will help in predicting how populations and ecosystems are likely to respond to the changes in climate occurring as greenhouse gases accumulate in the atmosphere. But they will also help to provide more complete explanations of the past. Until now evolutionary responses to changing environments have hardly been considered in the vast literature about the late Quaternary. In contrast, genetic theory, models and experiments that deal with adaptation to a continuously changing environment are progressing rapidly. By using knowledge from the past we may be able to accelerate research into the mechanisms of adaptation to changing environments, obtaining a more complete understanding of the past as well as more realistic predictions of the future.

\section{ACKNOWLEDGMENTS}

Our particular thanks go to the editors of this Special Feature, Linda Brubaker, Lisa Graumlich, and Shinya Sugita. We received stimulating comments and criticism from reviewers David Ackerly and Brian Huntley, and from Gerald Rehfeldt, Linda Brubaker, Eric Lonsdorf, Stacy Halpern, and Bryan Holtz. We also express our gratitude to Christine Douglas, James Ferrari and numerous undergraduate assistants for compiling the data presented in Table 1. We apologize to the many authors whose work on this subject could not be cited because of space limitations. Readers who wish a more complete list of references should consult the Appendix. This work was supported by the National Science Foundation (grants DMS 0083468 and DEB9221371), the Guggenheim Foundation, and by the Mellon Foundation.

\section{Literature Cited}

Ackerly, D. D. 2003. Community assembly, niche conservatism, and adaptive evolution in changing environments. International Journal of Plant Science 164:S165-S184.

Antonovics, J. 1976. The nature of limits to natural selection. Annals of the Missouri Botanical Garden 63:224-247.

Barton, N. H. 2001. Adaptation at the edge of a species' range. Pages 365-392 in J. Silvertown and J. Antonovics, editors. Integrating ecology and evolution in a spatial context. Special Symposia of the British Ecological Society, Blackwell Science, Oxford, UK.

Bennett, A. F., R. E. Lenski, and J. E. Mittler. 1992. Evolutionary adaptation to temperature. I. Fitness responses to Escherichia coli to changes in its thermal environment. Evolution 46:16-30.

Bennett, K. D. 1997. Evolution and ecology: the pace of life Cambridge University Press, Cambridge, UK.

Bürger, R., and M. Lynch. 1995. Evolution and extinction in a changing environment: a quantitative genetic analysis. Evolution 49:151-163.

Carter, K. K. 1996. Provenance tests as indicators of growth response to climate change in 10 north temperate tree species. Canadian Journal of Forestry Research 26:10891095

Case, T. J., and M. L. Taper. 2000. Interspecific competition, environmental gradients, gene flow and coevolution of species' borders. American Naturalist 155:583-605.

Clark, J. S., et al. 1998. Reid's paradox of rapid plant migration: dispersal theory and interpretation of paleoecological records. BioScience 48:13-24.

Clausen, J., D. D. Keck, and W. M. Hiesey. 1940. Experimental studies on the nature of species. I. The effect of varied environment on western North American Plants. Publication 520. Carnegie Institution of Washington, Washington, D.C., USA.

Comes, H. P., and J. W. Kadereit. 1998. The effect of Quaternary climatic changes on plant distribution and evolution. Trends in Plant Science 3:432-438.

Cruzan, M. B., and A. R. Templeton. 2000. Paleoecology and coalescence: phylogeographic analysis of hypotheses from the fossil record. Trends in Ecology and Evolution 15:491496.

Cwynar, L. C., and G. M. MacDonald. 1987. Geographic variation of lodgepole pine in relation to population history. American Naturalist 129:463-469.

Davis, M. B., and R. G. Shaw. 2001. Range shifts and adaptive responses to Quaternary climate change. Science 292: 673-679.

Etterson, J. R. 2004a. Evolutionary potential of Chamaecrista fasciculata in relation to climate change: I. Clinal patterns of selection along an environmental gradient in the Great Plains. Evolution 58: 1446-1458.

Etterson, J. R. 2004b. Evolutionary potential of Chamaecrista fasciculata in relation to climate change: II. Genetic architecture of three populations reciprocally planted along an environmental gradient in the Great Plains. Evolution 58: 1459-1471.

Etterson, J. R., and R. G. Shaw. 2001. Constraint to adaptive evolution in response to global warming. Science $294: 151-$ 154.

García-Ramos, G., and M. Kirkpatrick. 1997. Genetic models of adaptation and gene flow in peripheral populations. Evolution 51:21-18.

García-Ramos, G., and D. Rodriguez. 2002. Evolutionary speed of species invasions. Evolution 56:661-668.

Gomulkiewicz, R., and R. D. Holt. 1995. When does evolution by natural selection prevent extinction. Evolution 49:201-207. 
Hairston, N. G., C. M. Kearns, L. P. Demma, and S. W. Effler 2005. Species-specific Daphnia phenotypes: a history of industrial pollution and pelagic ecosystem response. Ecology 86:1669-1678

Hairston, N. G., Jr., W. Lampert, C. E. Caceres, C. L. Holtmeier, L. J. Weider, U. Gaedke, and D. M. Post. 1999. Rapid evolution revealed by dormant eggs. Nature 401:466.

Hamrick, J. L., A. F. Schnabel, and P. V. Wells. 1994. Distribution of genetic diversity within and among populations of Great Basin conifers. Pages 147-161 in K. T. Hager, L. L. St. Clair, K. H. Thome, and W. W. Witters, editors. Natural history of the Colorado Plateau and Great Basin. University of Colorado Press, Niwot, Colorado, USA.

Hewitt, G. 2000. The genetic legacy of the Quaternary ice ages. Nature 405:907-913.

Huntley, B. W. Cramer, A. V. Morgan, H. C. Prentice, and J. R. M. Allen. 1997. Predicting the response of terrestrial biota to future environmental changes. Pages 487-504 in B. Huntley, W. Cramer, A. V. Morgan, H. C. Prentice, and J. R. M. Allen, editors. Past and future rapid environmental changes: the spatial and evolutionary responses of terrestrial biota. NATO ASI Series. Volume I 47. Springer-Verlag, Berlin, Germany.

Hurme, P. R. Repo, O Savolainen, and T. Paakkonen 1997. Climatic adaptation of bud set and frost hardiness in Scots pine (Pinus sylvestris). Canadian Journal of Forest Research 27:716-723.

Jackson, S. T. 2000. Out of the garden and into the cooler? A Quaternary perspective on deep- time paleoecology. Pages 287-308 in A. Gastaldo and W. A. DiMichele, editors. Evolution of phanerozoic terrestrial ecosystems. Paleontological Society Papers. Volume 6. New Haven, Connecticut, USA.

Jackson, S. T., and C. Weng. 1999. Late Quaternary extinction of a tree species in eastern North America. Proceedings of the National Academy of Science (USA) 96:1384713852

Kerfoot, W. C., J. A. Robbins, and L. J. Weider. 1999. A new approach to historical reconstruction: combining descriptive and experimental paleolimnology. Limnology and Oceanography 44:1232-1247.

Kirkpatrick, M., and N. H. Barton. 1997. Evolution of a species range. American Naturalist 150:1-23.

Lacey, E. P. 1988. Latitudinal variation in reproductive timing of a short-lived monocarp, Daucus carota (Apiaceae). Ecology 69:220-232

Lenski, R. E. 2001. Testing Antonovics' five tenets of ecological genetics: experiments with bacteria at the interface of ecology and genetics. Pages $25-45$ in M. C. Press, N. J. Huntly, and S. Levin, editors. Ecology: achievement and challenge. Blackwell Science, Oxford, UK

McGraw, J. B., and N. Fetcher. 1992. Response of tundra plant populations to climatic change. Pages 359-376 in F. Chapin, editor. Arctic ecosystems in a changing climate. Academic Press, New York, New York, USA.
Mongold, J. A., A. F. Bennett, and R. E. Lenski. 1999 Evolutionary adaptation to temperature. VII. Extension of the upper thermal limit of Escherichia coli. Evolution 53:386394

Muona, O. 1990. Population genetics in forest tree improvement. Pages 282-298 in A. H. Brown, M. T. Clegg, A. L. Kahler, and B. S. Weir, editors. Plant population genetics, breeding, and genetic resources. Sinauer, Sunderland, Massachusetts, USA

Pease, C. M., R. Lande, and J. J. Bull. 1989. A model of population growth, dispersal, and evolution in a changing environment. Ecology 70:1657-1664

Peterson, A. T, J Soberon, and V Sanchez-Cordero 1999. Conservatism of ecological niches in evolutionary time. Science 285: 1265-1267.

Prentice, C., P. J. Bartlein, and T. Webb, III. 1991. Vegetation and climate change in eastern North America since the last glacial maximum. Ecology 72:2038-2056.

Rehfeldt, G. E., N. M. Tchebakova, and E. I. Parfenova. 2004. Genetic responses to climate and climate-change in conifers of the temperate and boreal forests. Recent Research and Developments in Genetics and Breeding 1:113-130.

Rehfeldt, G. E., J. M. Tchebakova, Y. I. Parfenova, W. R. Wykoff, N. A. Kuzmina, and L. I. Milyiutin. 2002. Intraspecific response to climate in Pinus sylvestris. Global Change Biology 8:1-18

Rehfeldt, G. E., C. C. Ying, D. L. Spittlehouse, and D. A. Hamilton, Jr. 1999. Genetic responses to climate in Pinus contorta: niche breadth, climate change, and reforestation. Ecological Monographs 69:375-407.

Reinartz, J. A. 1984. Life history variation of common mullein (Verbascum thapsus). I. Latitudinal differences in population dynamics and timing of reproduction. Journal of Ecology 72:897-912.

Suyama, Y., K. Kawamuro, I. Kinoshita, K. Yoshimura, Y. Tsumura, and $\mathrm{H}$. Takahara. 1996. DNA sequence from fossil pollen of Abies spp. from Pleistocene peat. Genes and Genetic Systems 71:145-149.

Tani, N., N. Tomaru, M. Araki, and K. Ohba. 1996. Genetic diversity and differentiation in populations of Japanese stone pine (Pinus pumila) in Japan. Canadian Journal of Forest Research 26:1454-1462.

Turreson, G. 1922. The genotypic response of the plant species to the habitat. Hereditas 3:211-350

Webb, T., III. 1997. Spatial response of plant taxa to climate change: a palaeoecological perspective. Pages 57-72 in B. Huntley, W. Cramer, A. V. Morgan, H. C. Prentice, and J. Allen, editors. Past and future rapid environmental changes: the spatial and evolutionary responses of terrestrial biota. Springer-Verlag, Berlin, Germany.

Weber, E., and B. Schmid. 1998. Latitudinal population differentiation in two species of Solidago (Asteraceae) introduced into Europe. American Journal of Botany 85:11101121 .

\section{APPENDIX}

A complete bibliography of references used in preparing the review is available in ESA's Electronic Data Archive: Ecological Archives E086-092-A1 